\title{
Quebec medical schools slow to adopt pass/fail system
}

Cite as: CMAJ 2017 December 4;189:E1499-500. doi: 10.1503/cmaj.109-5525

Posted on cmajnews.com on Nov. 13, 2017.

$\mathbf{T}$ he Université de Sherbrooke's medical school is the latest in Canada to eliminate grades. The school had a pass/fail clinical clerkship and will now use that evaluation system for the first two years of medical school.

"We wanted students to work with each other on a collaborative state of mind, rather than a competitive state of mind," says Dr. Dominique Dorion, dean of medicine at Sherbrooke.

All but two Canadian medical schools now have a pass/fail system for all years of medical school. The exceptions are Université Laval and the Université de Montréal.

But Laval is also considering making the switch. Last year, a committee created by the medical education program recommended that the university look into the steps necessary to implement a pass/fail system. "It has to be approved by the university," says Dr. Claude Labrie, medical program director at the school. "I think there are only positives."

Quebec's medical student federation (FMEQ) has been advocating for years for a pass/fail system, which has been used at most medical schools outside Quebec for more than a decade.

"The major argument against a pass/ fail system is that students will study less and will perform less well," explains Samuel Bergeron, president of FMEQ. "We totally don't agree with this argument; in fact, there are studies that show the opposite."

Studies have shown that the pass/fail system reduces students' anxiety levels, encourages greater cooperation among medical students, and doesn't have a negative effect on academic performance.

Pass/fail is more suited to today's online world, says Kaylynn Purdy, vicepresident of education at the Canadian Federation of Medical Students and a fourth-year medical student at the Northern Ontario School of Medicine. "We can look up information in seconds; we don't necessarily need to memorize the Krebs cycle," she says. "The biggest focus of a pass/fail system is how do you study to be a good doctor, not how do you study to learn the facts."

Daniel Kurtz, a fourth-year medical student at Wayne State University in Detroit, which has a graded system through all four years, adds that the pressure of grades can cause students to limit the time they spend on learning opportunities outside the classroom. "Most of my peers have focused on coursework. They don't feel they can do the volunteering or research or job shadowing."

Kurtz also worries that grades can lead students into ill-fitting specialty choices. "I have friends who think that because they 'honoured' everything, they should go into dermatology or orthopedic surgery, because that's what they're being told. It doesn't end up matching people to the places they want to be."

Despite the evidence for pass/fail, other types of evaluation systems remain common in the United States. Out of 142

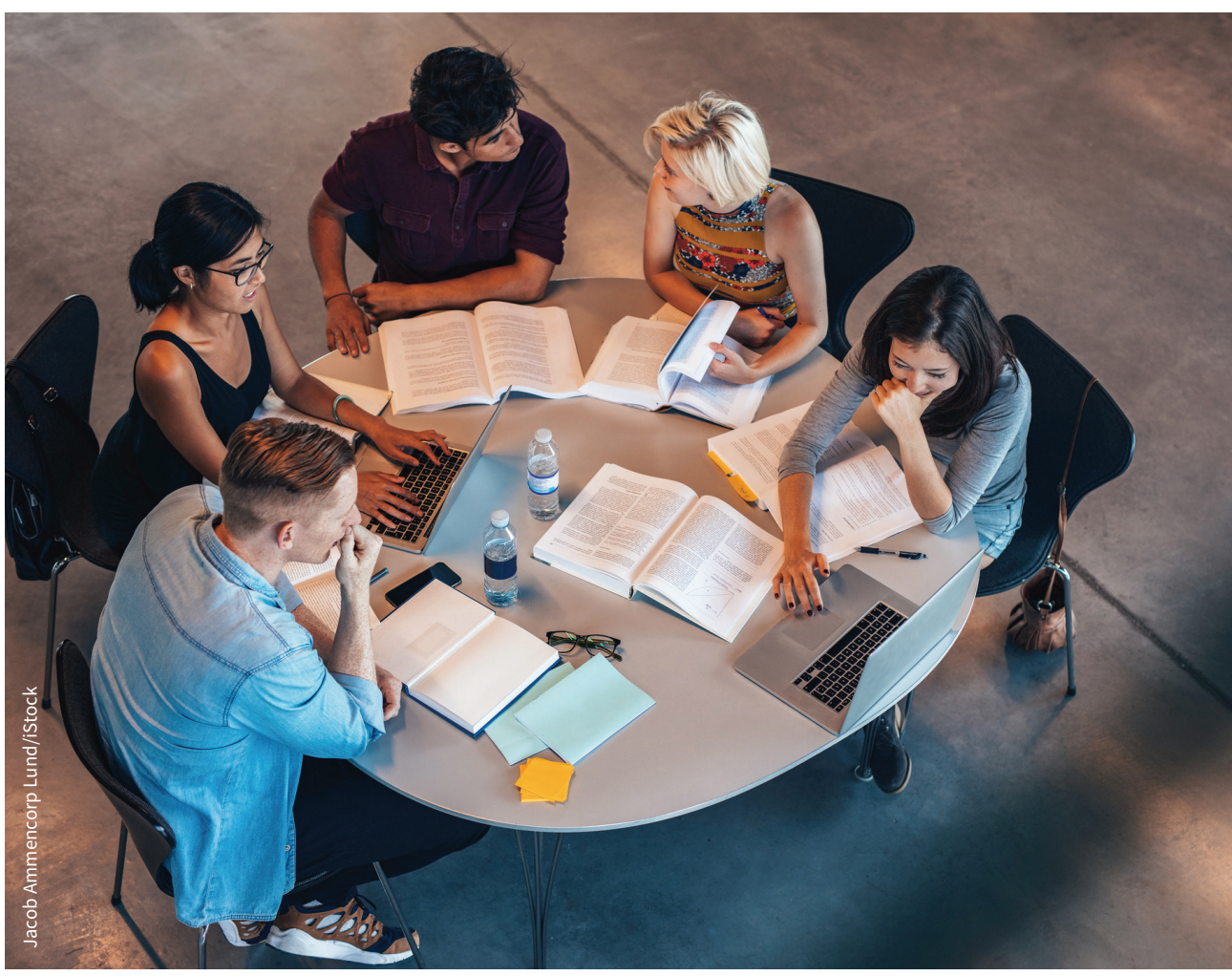

Medical schools have adopted pass/fail systems to reduce competition between students and encourage collaboration. 
schools surveyed by the Association of American Medical Colleges, 89 use pass/ fail for pre-clerkship years and only 14 for clinical clerkships. Honours/high pass/ pass/fail is the most common system for clerkships.

When Harvard Medical School changed its curriculum two years ago, administrators decided to do away with grades for the second-year clerkship. "It really aligns with our philosophy of focusing on a growth mindset, as opposed to focusing on test performance," says Dr. John Dalrymple, director of assessment, professionalism and humanism in medicine at the school. "We would hate for that performance so early on to carry so much weight in residency applications."
But administrators wanted to be sure they weren't putting students at a disadvantage when it came to residency choices, which is why they felt grades for the third and fourth years remained necessary, says Dalrymple. "Residency program directors want to see grades."

Wendy Glauser, Toronto, Ont. 